\title{
Researching the Problem and Countermeasure about Ecological Poverty Alleviation in Yunnan Province of China
}

\author{
Yongqian Li, Yerong $\mathrm{Li}^{*}$ \\ Faculty of Economics and Management, Yunnan Agricultural University, XiaoKanDaDao Street, Kunming \\ City, Yunnan Province, P. R. China \\ E-mail: 13987162465@163.com \\ E-mail: leeyr1965@163.com \\ *Corresponding author
}

Keywords: Ecological Environment Construction, Poverty Alleviation, Yunnan Province

\begin{abstract}
There is a causal relationship between fragileness of ecological environment and poverty, which determines that the ecological environment construction and poverty alleviation must be balanced. This article analyzes the relationship between the construction and poverty through the examples of Yunnan Province, from the point of view of both the restoration of ecological system and the development of ecological economy, and puts forward the concrete measures of constructing ecological engineering, building eco-tourism areas and innovating new modes of labor transfer and so on. In the end, it is concluded that we need to carry out the ecological poverty alleviation better and provide policy support for effectively solving the problem of poverty and ecological environmental deterioration.
\end{abstract}

\section{Introduction}

This phenomenon in the process of social economic development in China is common: Excessive reclamation of poor groups leads to soil and water loss; sparse grassland over grazing led to grassland degradation. This shows poverty and ecological environment construction in which it is a certain correlation. Poverty often leads to the deterioration of the ecological environment, and the deterioration of the ecological environment makes the poor groups more difficult to survive and develop. Yunnan is a plateau mountainous province, mountainous area accounts for $94 \%$ of the total land area.70\% of the population and $80 \%$ of the minority nationalities are distributed in the mountains, the stand or fall of the ecological environment has a huge influence on the impoverished mountainous area people's life and the whole province's economic development, the reconstruction and restoration of the ecosystem provide a support for the good circulation of people's production and life, and lay a solid foundation for economic growth and sustainable development of society. From the perspective of sustainable development, ecological environment construction to enter a virtuous cycle which is effectively promoted the regressive co-ordination of the regional system of main land relationship, at the same time also has the great significance for poverty alleviation in Yunnan.

The contradiction is still prominent between economic development and ecological protection in poor areas. Although the trend of eco-environmental deterioration in poor areas has been initially curbed, the livelihood of farmers in the ecological environment protection area has not been settled. About more than 50\% of the land area in Yunnan province is divided into natural forest conservation, ecological public welfare forest area and nature reserves, is the upstream area of the river, is the China's Yangtze River, the Pearl River basin ecological barrier of homeland security, the vast majority of these regions for the poor areas, where the forests and other natural resources are freely allocated, and there is no alternative means of livelihood. So, it makes some poor areas mainly depending on the development of the resources in a dilemma. The contradiction is very outstanding on poverty alleviation development and environmental protection. 


\section{The present situation and problem analysis of the ecological environment construction and poverty alleviation in Yunnan province}

\subsection{The present situation of ecological environment construction in Yunnan}

Within the territory of Yunnan province belongs to the high altitude low latitudes, complicated geographical environment, light, heat, water, soil, land, air and other natural resources distribution of space and time difference is very big. In short, it is fragile ecological environment. Especially in recent decades, along with the social change, economic development, regional remain open, onesided pursuit of economic interests while ignoring the ecological environment construction and even to destroy the ecological environment for the economic benefits, these are increasingly common. The total land area of Yunnan province is $394,000 \mathrm{~km}^{2}$, mountain area accounted for about 94\%, inter mountain basin is only 6\%. The special geographical position determines the ecological environment construction in Yunnan to have significant influence on the social economy of the basin. Geographical environment complicated congenital factors, and the unreasonable use of natural resources of human factors, is the main cause of the fragile ecological environment in Yunnan, is of great importance to strengthen ecological environment construction.

\subsection{The present situation of ecological poverty alleviation in Yunnan province}

Due to the adverse factors such as nature and society, Yunnan province has a relatively backward economic development, with a large poverty level, a deep level poverty and difficult for poverty alleviation. Currently, there are 73 poverty-stricken counties. Especially in the minority areas, mostly in poor areas and ecologically fragile areas, and there are 78 Ethnic Autonomous counties in Yunnan province, the total population of ethnic minorities accounted for $48 \%$ of the total population, according to the poverty standard of 2300 Yuan, the current population is about 3802.3 thousand, poverty incidence is as high as $20.6 \%$. Since 2002, ecological industry construction of Yunnan province has made remarkable achievements, implemented a series of ecological construction projects such as the construction of "Forest Yunnan", the protection of biodiversity, the transformation of middle-low yield forests and the conversion of farmland to forests, through forest plantation, a good ecological environment has become a solid foundation for sustainable economic and social development in Yunnan, making ecological industrialization an effective development path for the masses to get rid of poverty.

\subsection{The problems of ecological environment construction}

Yunnan province is located in the Yangtze River shelter-forest area in China. Due to years of over-exploitation, the serious vegetation destruction, the forest coverage rate has dropped from 50\% to $25 \%$, in recent years, due to the implementation of forest protection measures, the forest coverage rate is back to $44.29 \%$, but for forest plantation time short, forest overall quality is not high. Terrain for the plateau mountainous area of Yunnan province, the high and steep mountain, ravines horizon, shallow soil layer, and a long-term excessive logging, forest vegetation destroyed, and the effect of ecological environment construction is not obvious. At present, the area of soil erosion in Yunnan province accounts for $36.7 \%$ of the land area, which covers 115 counties and cities in 16 states and cities in the province. Rocky desertification situation in Yunnan province is seen the table 1.

Table 1 Rocky desertification degree table in Yunnan Province

\begin{tabular}{lccc}
\hline Rocky desertification degree & Area (ten thousand $\mathrm{km}^{2}$ ) & $\begin{array}{l}\text { Percentage of the total area } \\
\text { of the occupied rocky } \\
\text { desertification (\%) }\end{array}$ & Note \\
\hline Rocky desertification area in Yunnan & 0.95 & $61.16 \%$ & $\begin{array}{l}2.15 \% \text { of the province's } \\
\text { land area }\end{array}$ \\
$\begin{array}{l}\text { Bare rock rate }>70 \% \\
30 \%<\text { Bare rock rate }<70 \%\end{array}$ & 0.6 & $31.58 \%$ & $\begin{array}{l}\text { Accounting for } 1.87 \% \\
\text { of the province's land } \\
\text { area }\end{array}$ \\
Potential rocky desertification land & 0.3 & 0.7 & \begin{tabular}{l} 
and \\
\hline
\end{tabular}
\end{tabular}

As we can see from the table, the total area of rocky desertification in Yunnan Province is 9,500 
$\mathrm{km}^{2}$, accounting for $2.15 \%$ of the total land area. There are $6,000 \mathrm{~km}^{2}$ of rocky mountain where the exposed rate of bedrock is more than $70 \%, 3000 \mathrm{~km}^{2}$ of rocky desertification land with $30 \%-70 \%$ nudity of bedrock, and $7,000 \mathrm{~km}^{2}$ of rock with potential rocky desertification.

Yunnan Province is a frequently natural disasters area. The main natural disasters are landslides, landslides, mudslides, frost and droughts. Taking geological disasters as an example, a total of 346 geological disasters occurred in Yunnan Province in 2015. The distribution of the Fig 1.

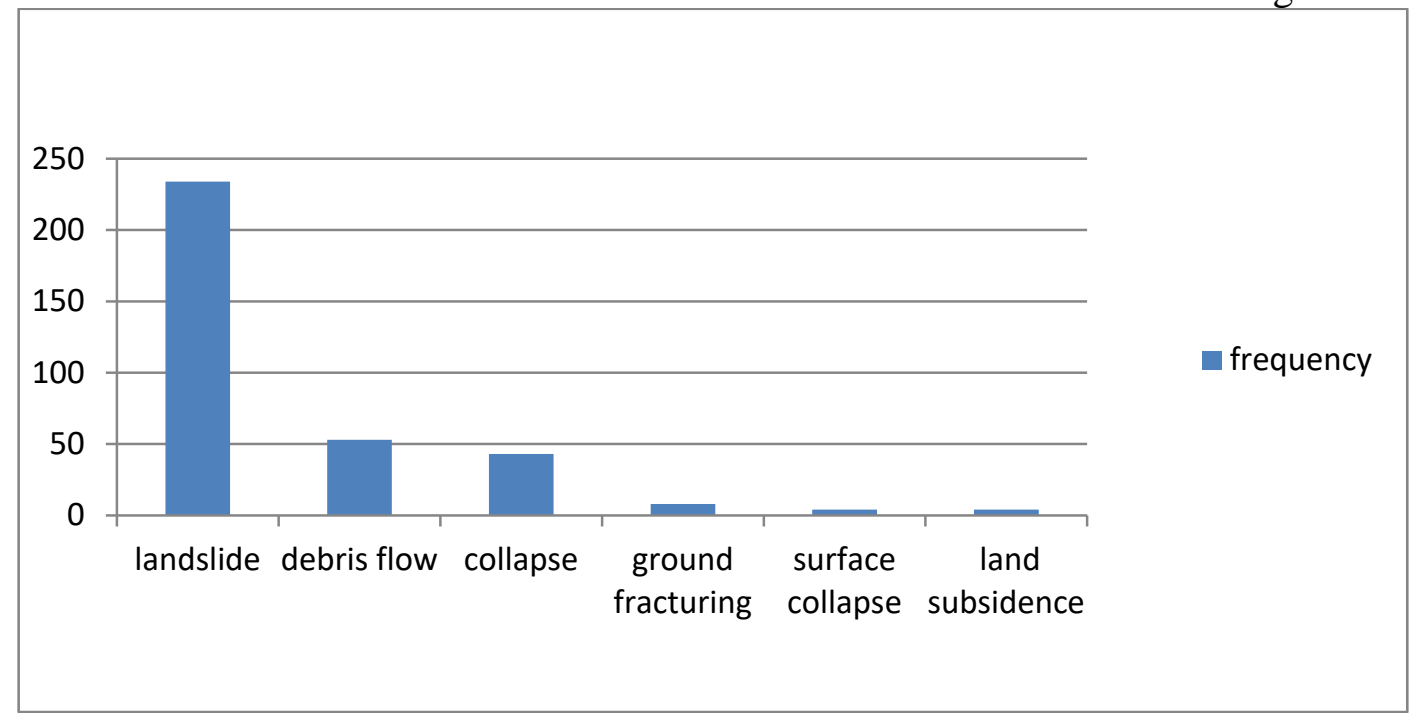

Fig.1 Bar chart for disaster occurrence by disaster type in 2015

According to the disaster scale, there were four super-huge geological disasters, 1 large-scale geological disaster, 18 medium-sized geological disasters and 323 small-scale geological disasters. Geological disaster caused a total of 17 people's death, 5 were missing, 27 were injured, and the direct economic loss was 275.6 million Yuan. Disaster occurrence pie chart is as Fig 2.

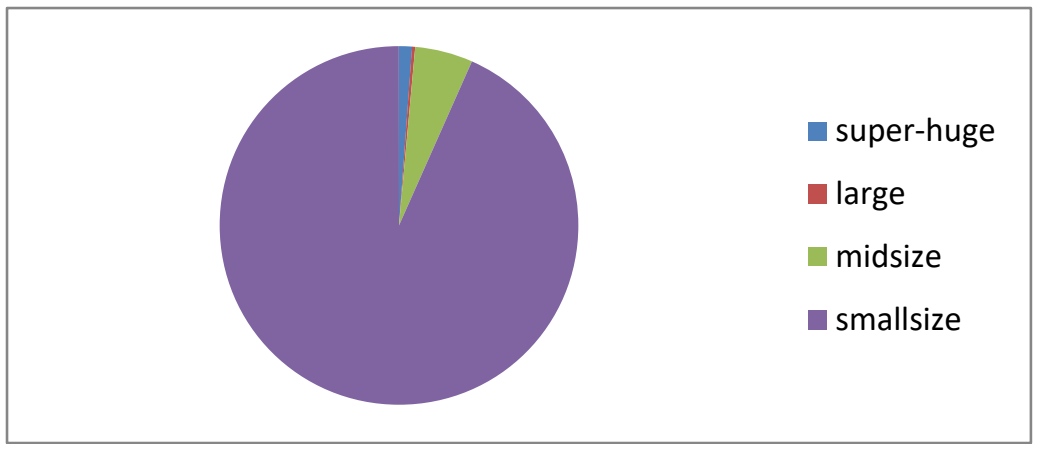

Fig.2 Classification of disaster occurrence by pie chart in 2015

Topography of Yunnan is complex and diverse, which leads to great disparities in natural resources and even social resources. There are large differences in traffic conditions in Yunnan province.

\section{Conclusion}

\subsection{Comprehensively promoting the "village appearance renovation" project}

Based on the existing basic conditions, integrate resources, circling with water, roads, sanitation, energy, etc. which are the most urgent and focus on issues for the poor, to carry out the benefit from the most direct small public facilities construction projects. Such as road mending, water diversion, kitchen modification, etc. Through the implementation of the village appearance renovation projects, the poor group has not only enjoyed the benefits of poverty alleviation, but also the beautiful rural living environment. 


\subsection{Development of characteristic forest and fruit industry}

The complex and diverse natural environment in Yunnan provides a unique condition for the development of characteristic fruit industries. The specialized forest industry can not only adjust the industrial structure of the rural areas, promote the increase of farmers' income, accelerate the poverty alleviation and become rich in the mountain areas, but also promote the improvement of the ecological environment.

\subsection{Improving the biological defense system of natural disasters}

Establish a more perfect biological defense system for natural disasters, especially the defense system of geological disasters. Such as the construction of bio ecological engineering in the areas of geological disasters, prohibit deforestation reclamation cultivated in protected areas, to create different types of forest, rational cultivation of forest and herbaceous vegetation shrub can protect soil on the slope, but also can improve the disaster area of vegetation coverage rate to realize the ecological environment of the disaster area into a virtuous cycle.

\subsection{Building a large area of Ecotourism}

The ecotourism not only protects the environment but also develops the local economy, which is method to kill two birds with one stone for construction of ecological environment and poverty alleviation. To explore the characteristic of local ecological resources at maximum, fully protect the remaining of the original ecological environment, deeply mine core ecological tourism resources to develop the ecological tourist areas with the local characteristics.

\subsection{Further reform the low-yielding land}

According to the local conditions, it needs to implement the slope improvement and fertilizing projects to achieve the soil improvement. It is necessary to mobilize the masses to accumulate agricultural manure and fertilize the soil. Meanwhile, we should increase the surface of soil thickness to enrich the soil, and accelerate the release of nutrients from the soil.

\section{Acknowledgements}

This paper is an achievement of fund project supported by National Planning

Office of Philosophy and Social Science named Study on Rural Chronic Poverty in West Minority Areas Based on Ecological Security Perspective.

Project Number:17BJY130

\section{References}

[1] Xu Jiayan. Analysis of ecological environment protection of Nanjian River [J]. Yunnan environmental science 2006 (25): 18-19.

[2] Wang Yingxue. Empirical analysis of Yunnan eco-type anti-poverty [J]. Management observation 2009: 21-22.

[3] Deng Jufen. Stony desertification and comprehensive governance in karst area of Yunnan [J]. Science of grass industry.2009.26 (2): 33-38.

[4] Zhang Xueqing. Ecological tourism: new ideas for ecological restoration and poverty alleviation in Wumeng Mountain [J]. Anhui agricultural science.2010.38 (13): 6981-6983.

[5] Chen Chunxia. Reflections on the construction and sustainable development of ecological environment in poor mountainous areas in China [J]. Western technology of China.2010 (32): 42-44. [6] Huang Shuxun, Cha longfen, Dong jiaze. Nanjian County, with the "five new model" mode, is devoted to the construction of new rural areas [J]. Yunnan rural economy 2010 (1): 14-16.

[7] Song Yuan. Thinking on the development strategy of rural poverty alleviation in Yunnan in the next ten years [J]. Social science in yunnan.2011 (5): 86-90. 